\title{
Important problems of future thermonuclear reactors*
}

Marek J. Sadowski

\begin{abstract}
This paper concerns important and difficult problems connected with a design and construction of thermonuclear reactors, which have to use nuclear fusion reactions of heavy isotopes of hydrogen, i.e., deuterium (D) and tritium (T). There are described conditions in which such reactions can occur, and different methods of a high-temperature plasma generation, i.e., high-current electrical discharges, intense microwave pulses, and injection of energetic neutral atoms (NBI). There are also presented experimental facilities which can contain hot plasma for an appropriate period, and particularly so-called tokamaks. The second part presents the technical problems which must be solved in order to build a thermonuclear reactor, that might be used for energetic purposes. There are considered problems connected with a choice of constructional materials for a vacuum chamber, its internal parts, external windings generating a magnetic field, and necessary shields. The next part considers the handling of radioactive tritium; the using of alpha particles $\left({ }^{4} \mathrm{He}\right)$ for additional heating of plasma; recuperation of hydrogen isotopes absorbed in the tokamak internal parts, and a removal of a helium excess. There is presented a scheme of a future thermonuclear power plant and critical comments on a road map which should enable the construction of an industrial thermonuclear reactor (DEMO).
\end{abstract}

Key words: fusion reactions $\bullet$ plasma $\bullet$ tokamak $\bullet$ power plant $\bullet$ thermonuclear reactor

\section{J. Sadowski}

Plasma Studies Division (TJ5),

National Centre for Nuclear Research (NCBJ),

7 Andrzeja Soltana Str., 05-400 Otwock/Swierk, Poland and Division of Magnetised Plasma,

Institute of Plasma Physics and Laser Microfusion (IPPLM)

23 Hery Str., 01-497 Warsaw, Poland,

Tel.: +48 22273 1537, Fax: +48 22779 3481,

E-mail: marek.sadowski@ncbj.gov.pl

Received: 3 August 2014

Accepted: 1 December 2014

\section{Introduction}

During the recent 400 years, the world population has grown more than ten-fold to the 6.5 billion people that today inhabit the Earth. Over the next 50 years the world's population is expected to grow from the present value to a level in the range 8-12 billion, and energy needs are expected to double or even triple during that period. Therefore, it is a major challenge to provide these people with clean and safe energy sources. At present, almost $80 \%$ of the energy production comes from fossil fuels and their burning generates huge amounts of carbon dioxide $\left(\mathrm{CO}_{2}\right)$ which pollutes the environment, induces the greenhouse effects and extreme climate changes [1]. Energy from the so-called renewable sources is very dilute and its power per unit of surface used is low, e.g., from solar energy - (5-50) $\mathrm{W} / \mathrm{m}^{2}$, from hydro-energy about $11 \mathrm{~W} / \mathrm{m}^{2}$, from on-shore and off-shore wind $-(2-3) \mathrm{W} / \mathrm{m}^{2}$, and from biomass $-0.5 \mathrm{~W} / \mathrm{m}^{2}$ only [1]. For a substantial contribution renewable power production plants depend on the size and localization of a country. Appropriate installations are very large and costly, e.g., to produce about $70 \mathrm{GW}$ from photo-voltaic and on-shore wind installations

* This review paper is based on an invited lecture given at the Polish Energy Mix-2014 Conference held at Ustroń Śląski, Poland, on 15-17 October 2014. 


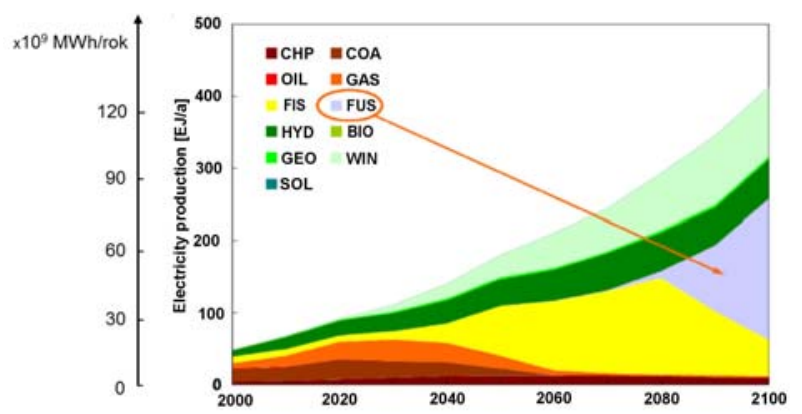

Fig. 1. Modelling of electric power production from different energy sources (COA - coal, OIL - petrol, GAS - gas, FIS nuclear fission, FUS - nuclear fusion, HYD - hydro-energy, $\mathrm{BIO}$ - bio-sources, GEO - geothermal, WIN - wind installations, SOL - solar installations, CHP - combined heat and power technologies), according to the English CCFE [2].

Germany spent about 24 billion Euro. Therefore, it is unrealistic to assume that energy in the future might be produced from a renewable sources only.

Nuclear energy from conventional nuclear reactors, which are based on the fission processes, is also not an option because such reactors produce huge amounts of radioactive wastes and are not completely safe during their exploitation. Hence, it seems that the only option for the future might be energy produced by thermonuclear reactors which might use nuclear fusion of heavy hydrogen isotopes, i.e. deuterium (D) and tritium (T). This opinion is shared by the Culham Centre for Fusion Energy (CCFE) experts [2], as shown in Fig. 1.

It should be noted that thermonuclear reactors will not produce any long-living radioactive wastes and they will not threaten any explosion, but there are many difficult technological issues to be solved before the first energetic fusion reactor is put into operation.

This paper describes the most important problems of future thermonuclear reactors. The first part presents physical principles of controlled nuclear fusion reactions, various methods of high-temperature plasma production, different devices used for plasma containment, and particularly tokamaks. The second part considers the most important problems connected with a design and construction of the tokamak-type thermonuclear reactor. The last part presents problems of fuel control and processing, the scheme of a future fusion energy plant and critical comments on a road map leading to the first industrial thermonuclear reactor.

\section{Generation and containment of high-temperature plasma}

As mentioned above, nuclear energy can be released not only by the fission of heavy nuclei, but also by the fusion of light nuclei into the heavier ones [3, 4]. An example of the fusion reaction is joining 4 protons into a helium nucleus. Probability of this process is very small, but it is realized through several intermediate reactions (the so-called p-p cycle) inside the Sun and many other stars. Although such fusion reactions run very slowly, due to gigantic dimensions of the Sun they deliver enough energy to keep very high temperature (about $15 \times 10^{6} \mathrm{~K}$ ) and to emit enormous amounts of radiation energy. It should be noted that inside very hot stars $\left(>10^{8} \mathrm{~K}\right)$ there occur other fusion reactions, e.g. ${ }^{13} \mathrm{C}+{ }^{4} \mathrm{He} \rightarrow{ }^{16} \mathrm{O}$ $+\mathrm{n}$. The produced neutrons can then be absorbed by heavy nuclei and produce still heavier elements. Since such fusion reactions occur at very high temperatures usually in a thermodynamic equilibrium state, they are called the thermonuclear reactions.

In order to master nuclear fusion, physicists have searched reactions possible in a laboratory [3-5], and it has been found that one can relatively easily realize the fusion of deuterium (D) and tritium (T) through several reactions, as shown in Fig. 2.

The D-D and D-T nuclear fusion reactions can be realized by appropriate acceleration of deuterons or tritons and the irradiation of targets containing deuterium or tritium, but such processes occur without thermodynamic equilibrium. Such reactions are not thermonuclear ones, and they do not ensure a positive energy balance. From the physical point of view, the fusion reactions are possible if the interacting nuclei have energy high enough to overcome the repulsion force of their positive charges (the Coulomb barrier). This can be achieved at very high temperatures, but in such conditions the matter is in the plasma state, i.e., constitutes a mixture of free electrons and positive ions or atomic nuclei. High-temperature plasma loses energy by an intense electromagnetic emission. Weakly ionized plasma emits different spectral lines, but at higher temperatures fully-ionized plasma emits a continuous spectrum, due to the ion-electron recombination and electron Bremsstrahlung. In such a state the energy distribution of electrons is often different from that of ions, but in spite of the lack of full equilibrium there are used such parameters as electron temperature $\left(T_{e}\right)$ and ion temperature $\left(T_{i}\right)$, usually expressed in electron-volts $[\mathrm{eV}]$, where $1 \mathrm{eV}$ corresponds to about $1.1 \times 10^{4} \mathrm{~K}$. With an increase in temperature, the efficiency of nuclear fusion increases faster, and the 'ignition temperature' is achieved when the energy released from fusion reactions is higher than the radiation losses. For pure deuterium plasma, it amounts to about $35 \mathrm{keV}$ (ca. $350 \times 10^{6} \mathrm{~K}$ ), while for a deuterium-tritium mixture it is equal to about $4.5 \mathrm{keV}$ (ca. $45 \times 10^{6} \mathrm{~K}$ ).

To master new energy sources, in the early 1950s, physicists in the USA performed tests of the

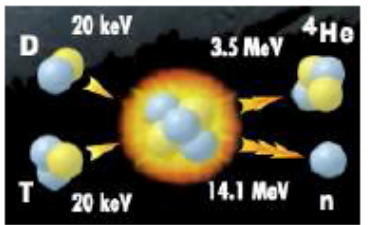

$$
\begin{aligned}
& { }^{2} D+{ }^{2} D \rightarrow{ }^{3} \mathrm{~T}+\mathrm{p}+4.0 \mathrm{MeV} \\
& { }^{2} \mathrm{D}+{ }^{2} \mathrm{D} \rightarrow{ }^{3} \mathrm{He}+\mathrm{n}+3.2 \mathrm{MeV} \\
& { }^{2} \mathrm{D}+{ }^{3} \mathrm{~T} \rightarrow{ }^{4} \mathrm{He}+\mathrm{n}+17.6 \mathrm{MeV} \\
& { }^{2} \mathrm{D}+{ }^{3} \mathrm{He} \rightarrow{ }^{4} \mathrm{He}+\mathrm{p}+18.4 \mathrm{MeV}
\end{aligned}
$$

$$
\begin{aligned}
& { }^{6} \mathrm{Li}+\mathrm{n} \rightarrow{ }^{4} \mathrm{He}+{ }^{3} \mathrm{~T}+4.8 \mathrm{MeV} \\
& { }^{6} \mathrm{Li}+\mathrm{p} \rightarrow{ }^{4} \mathrm{He}+{ }^{3} \mathrm{He}+3.9 \mathrm{MeV} \\
& { }^{6} \mathrm{Li}+{ }^{2} \mathrm{D} \rightarrow 2{ }^{4} \mathrm{He}+22.3 \mathrm{MeV}
\end{aligned}
$$

Fig. 2. Scheme of the D-T fusion reaction (left) and other important fusion reactions (middle and right). 
so-called enriched atomic bomb, which contained ${ }^{235} \mathrm{U}$ and some amounts of deuterium and tritium [6]. The first fully thermonuclear explosion, which was equivalent to 10 megaton TNT, was realized in 1952. About 10 months later, the Soviet Union performed the first thermonuclear explosion using the lithium reactions (see Fig. 2 - right). For a comparison - the fission of $1 \mathrm{~kg}$ of uranium produces energy equivalent to 20 kiloton TNT, while the fusion of $1 \mathrm{~kg}$ of ${ }^{6} \mathrm{LiD}$ can release energy of 68 kiloton TNT, and $1 \mathrm{~kg}$ of a D-T mixture - of 80 kiloton TNT [4, 6], but such powerful explosions could not be used for industrial purposes. Therefore, simultaneously with military tests, physicists have also tried to realize controlled nuclear fusion and to construct a thermonuclear reactor. These efforts were motivated by the fact that deuterium resources in water upon the Earth are about $10^{17} \mathrm{~kg}$, equivalent to energy of about $10^{24} \mathrm{kWh}$, while the present power consumption amounts to about $5 \times 10^{9} \mathrm{~kW}$.

In order to achieve positive energy balance in a thermonuclear reactor based on controlled fusion reactions, high-temperature plasma must have appropriate concentration and life-time, i.e. at a lower density $(n)$ the confinement time $(\tau)$ must be longer [3]. This condition is determined by the so-called Lawson criterion: for the D-D fusion one must obtain $n \tau>10^{16} \mathrm{~s} / \mathrm{cm}^{3}$, and for D-T fusion this product should be $>3 \times 10^{14} \mathrm{~s} / \mathrm{cm}^{3}$. Considering the dependence on plasma temperature $(T)$, it is more reasonable to use the so-called triple product $T n \tau_{E}$, where $\tau_{E}$ is the energy confinement time depending on the losses by electromagnetic- and corpuscular-radiation, particle diffusion, etc.

To produce and heat up plasma one can use different methods. The most simple is a powerful electrical discharge between electrodes placed inside a vacuum chamber and supplied form a high-voltage condenser bank. This technique has been used in the so-called Z-pinch facilities, where plasma confinement is realized by magnetic field produced by a very intense current flowing through this plasma [7]. The same techniques is applied in the so-called Plasma-Focus (PF) discharges which are performed between two coaxial electrodes. Although large Z-pinch devices (e.g. Z-machine in the USA) and large PF facilities (e.g. PF-1000 machine in Poland)

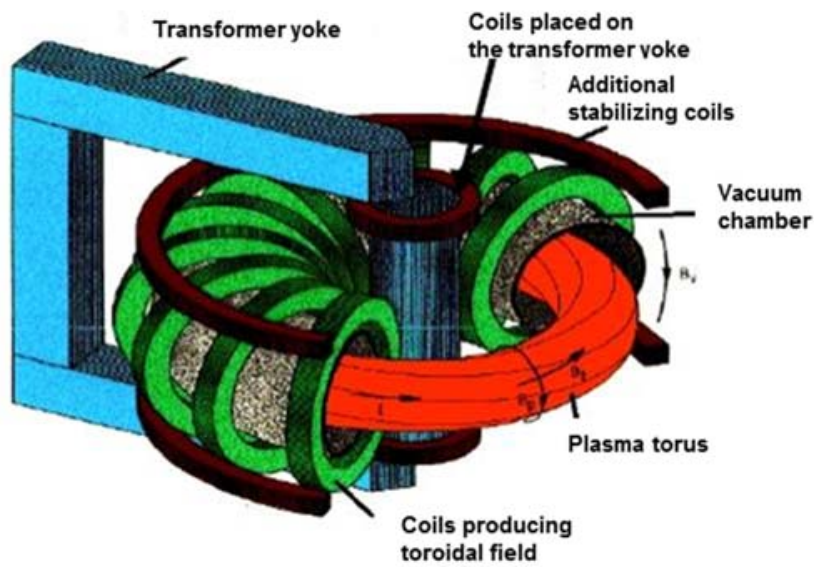

produce relatively high yields of fusion-produced neutrons (up to about $10^{12}$ per discharge) [7], it is not possible now to build an efficient thermonuclear reactor based on this principle.

Another important method is based on the production of very dense and hot plasma from a small target (containing D-T mixture) irradiated by a very powerful laser or particle beams. Plasma produced in such a way can have a very high density $\left(>10^{23} \mathrm{~cm}^{-3}\right)$ and temperature $(>5 \mathrm{keV})$, and be confined by its inertial effects long enough to produce a large number of fusion reactions. Such an 'inertial confinement' has been used in many laser-plasma experiments, e.g., in the very large laser system NIF (National Ignition Facility) use was made of 192 laser beams of the total energy equal to $1.9 \mathrm{MJ}$ converted into X-rays (inside a gold 'Hohlraum' cylinder) and concentrated upon a miniature fusion target (a 2.3-mm-diam. sphere containing a D-T mixture). During about 20-ns laser pulse, this target could absorb 8.5-12 kJ from laser radiation and produce 14.4-17.3 kJ energy from D-T fusion reactions [8], but the efficiency of the whole system was very low. Therefore, in spite of very fast development of laser technology and construction of new powerful laser systems (e.g. an LMJ in France), it is impossible in the near future to build an industrial thermonuclear reactor based on the 'inertial confinement'.

The most effective method to realize controlled fusion reactions seems now to be a 'magnetic containment' of plasma of thermonuclear parameters within the so-called tokamak [3], shown in Fig. 3.

In such magnetic traps plasma is induced inside a quasi-toroidal vacuum chamber (like in the secondary winding of a powerful transformer) and heated up by intense (up to several tens MW) electromagnetic pulses of different frequencies (ranging from $\mathrm{MHz}$ to $\mathrm{GHz})$ and/or intense high-energy $(80-100 \mathrm{keV})$ neutral atomic beams (NBI). Since the 50s of the previous century, many tokamaks have been constructed and investigated in different countries. The best results have been achieved with a large JET (Joint European Tokamak) facility operated in Culham, England [5]. In 1997, using a D-T mixture in JET there was produced about $16 \mathrm{MW}$ during about $2 \mathrm{~s}$ (i.e., there was obtained about $1.4 \times 10^{19}$ fusion neutrons) [9]. In the described experiments for plasma heating

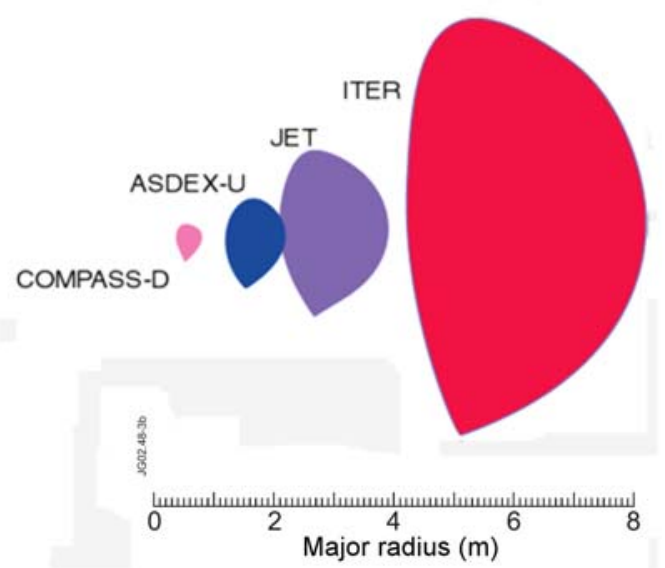

Fig. 3. Construction of a tokamak (left) and dimensions of different tokamaks (right). 
there were applied microwaves of $3 \mathrm{MW}$ power and neutral deuterium beams of $22 \mathrm{MW}$ power. This means that the positive energy balance has not been achieved, but the obtained results have became the basis for acceleration of efforts to build a new large ITER (International Thermonuclear Experimental Reactor) facility [10].

\section{Technological requirements for thermonuclear reactors}

The size of a thermonuclear reactor must be relatively large and its construction very complex, as shown in Fig. 4.

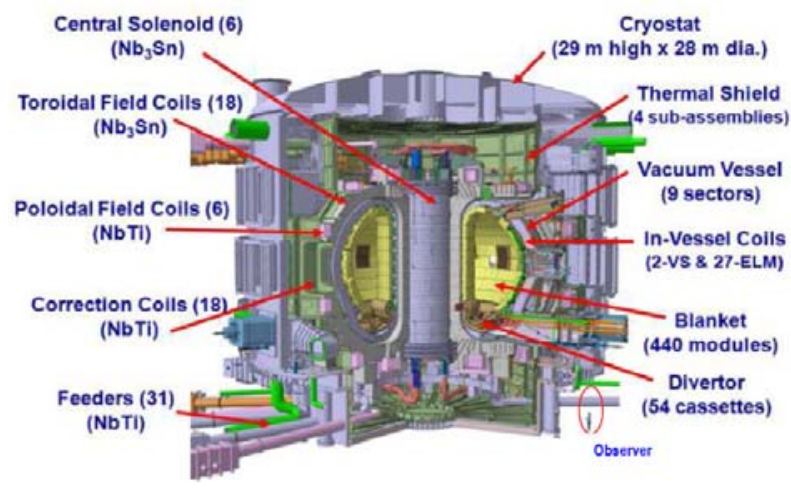

Fig. 4. Scheme of ITER with the main structural components marked by arrows [10].

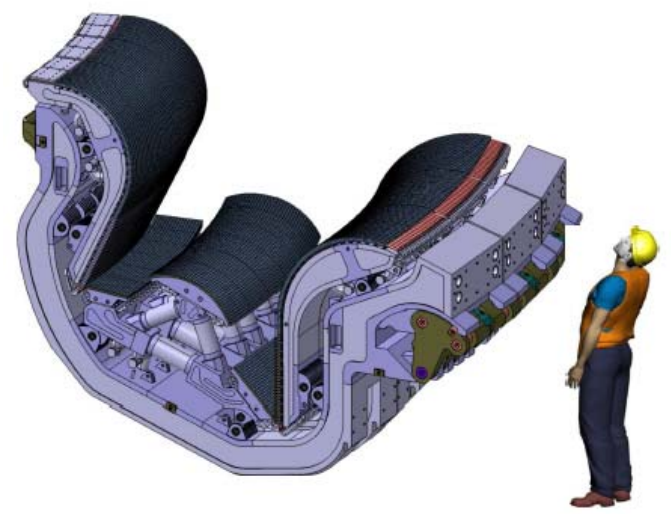

Fig. 5. Design of divertor modules for ITER [11].
All the main structural components, i.e., a vacuum vessel, plasma facing parts, the so-called divertor construction, blanket modules, tritium breeding modules, toroidal- and poloidal-field coils, cryostat for superconducting windings, plasma-heating and plasma-diagnostics systems, constructional supports, external shielding and appropriate power supplies, must be designed very carefully [11]

The main technical problems connected with the design of a vacuum vessel and plasma facing components are very high thermal and corpuscular loads. It is estimated that the plasma facing components must withstand thermal loads of the order of $1-3 \mathrm{MJ} / \mathrm{m}^{2}$ during the so-called ELMs (Egde Localized Modes) instabilities lasting $0.1-0.5 \mathrm{~ms}$, and $10-100 \mathrm{MJ} / \mathrm{m}^{2}$ when a 'disruption' of plasma discharge appears (during 1-10 ms). As regards corpuscular loads, the most important are fast fusion-produced neutrons which can induce serious degradation of the constructional materials. The first tokamaks were equipped with stainless-steel walls and had no neutron shield (blanket). The JET facility had pure carbon (graphite) internal walls, and recently it has been equipped with beryllium (Be) ITER-like walls. The ITER will have Be walls and a blanket, which will convert power of the $14-\mathrm{MeV}$ neutrons into heat and tritium breeding.

Another technical problem is the construction of a divertor (a bottom part of the vacuum vessel), as shown in Fig. 5.

The divertor (composed of 54 assemblies, ca. 8.7 tonnes each), due to the local inversion of magnetic field lines, is designed to collect heavy impurity ions from a near-wall plasma region, and to ensure efficient vacuum pumping through special slits and external cryopumps. Because of large thermal loads (up to $20 \mathrm{MW} / \mathrm{m}^{2}$ over $10 \mathrm{~s}$, and $5-10 \mathrm{MW} / \mathrm{m}^{2}$ over longer periods) the inner and outer divertor targets as well as its central part (dome) will be made from tungsten.

Although some portion of power carried out by alpha particles (about $20 \%$ of fusion power) will be used for plasma heating, the rest power must also be extracted by the first wall. It is estimated that in ITER there will be produced $500 \mathrm{MW}$ from D-T fusion, and at $40 \mathrm{MW}$ delivered for auxiliary plasma heating, only about $140 \mathrm{MW}$ will be consumed in

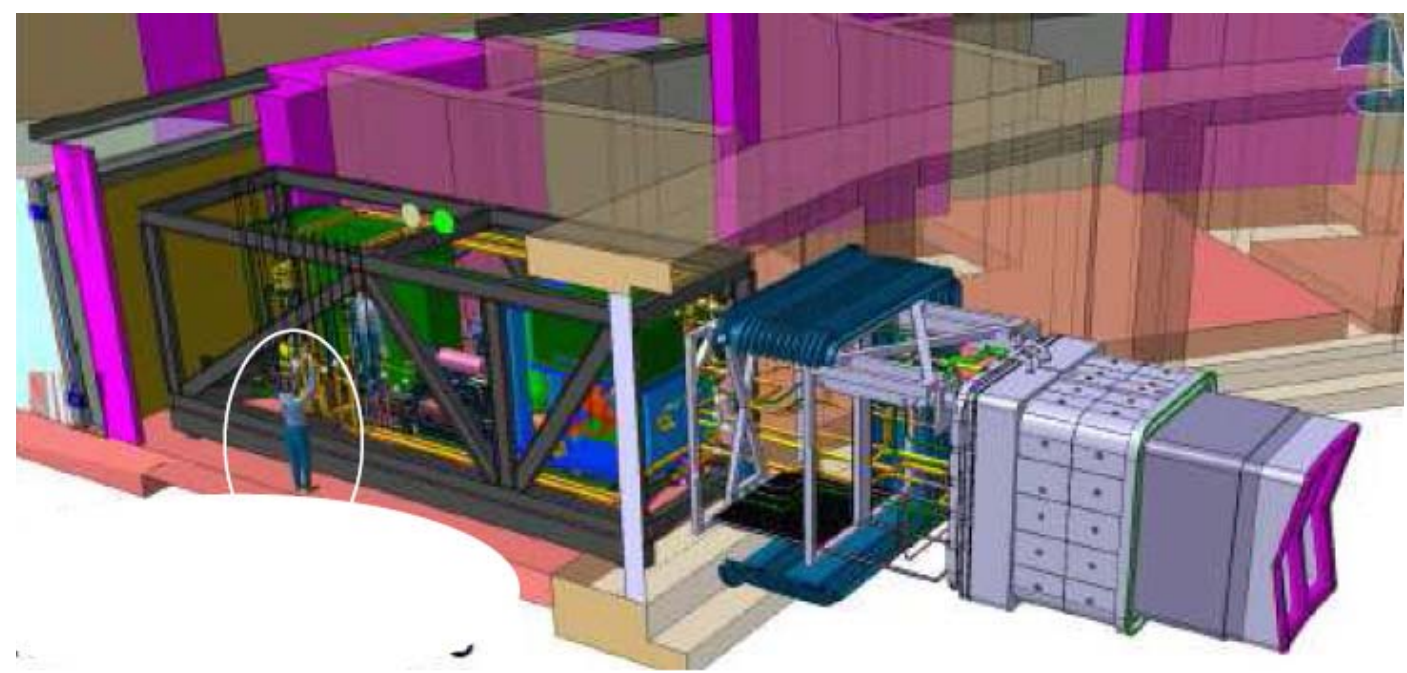

Fig. 6. Scheme of an ITER port with a TMB module [11] 
plasma, while $400 \mathrm{MW}$ (carried out by the fast neutrons) should be absorbed in a blanket. Therefore, in ITER each blanket module will be composed of a separable plasma-facing panel (covered with Be tiles) and a semi-permanent massive shielding block (total mass ca. $1800 \mathrm{t}$ ).

A difficult problem is the design of tritium breeding modules (TBM), which might use the neutron-lithium reactions: ${ }^{6} \mathrm{Li}+\mathrm{n} \rightarrow{ }^{4} \mathrm{He}+{ }^{3} \mathrm{~T}+4.8 \mathrm{MeV}$ and ${ }^{7} \mathrm{Li}+$ $\mathrm{n} \rightarrow{ }^{4} \mathrm{He}+\mathrm{T}+\mathrm{n}$ ' $-2.5 \mathrm{MeV}$. For neutron multiplication, one can also use neutron-beryllium reactions. Hence, different chemical compounds, e.g. $\mathrm{PbLi}, \mathrm{Li}_{2} \mathrm{O}$, $\mathrm{Li}_{2} \mathrm{ZrO}_{3}, \mathrm{Li}_{8} \mathrm{ZrO}_{6}, \mathrm{Li}_{2} \mathrm{TiO}_{3}, \mathrm{LiAlO}_{2}, \mathrm{Li}_{2} \mathrm{SiO}_{3}, \mathrm{Li}_{4} \mathrm{SiO}_{4}$,

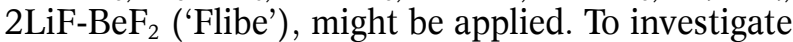
these materials all ITER parties are now involved in the construction of TBM and three ports of ITER will be used for their testing, as shown in Fig. 6.

A very difficult aim is the design and construction of large superconducting coils which should produce toroidal and poloidal components of the magnetic field as well as auxiliary control fields. An example of a large toroidal field coil is shown in Fig. 7.

The whole magnetic system of ITER will be composed of 18 toroidal field coils (total weight $6540 \mathrm{t}$ ), 6 central solenoid modules (total weight $974 \mathrm{t}$ ), 6 poloidal field coils (total weight $2163 \mathrm{t}$ ), 9 pairs of so-called correction coils (total weight $85 \mathrm{t}$ ), and 31 superconducting feeders [12]. The total length of superconducting cables (made of $\mathrm{Nb}_{3} \mathrm{Sn}$ or $\mathrm{NbTi}$ ) will amount to about $190 \mathrm{~km}$. In order to produce these superconducting coils large industrial facilities are under construction. It should be added that to stabilize plasma within the ITER vessel use will be made of additional in-vessel coils made of mineral-insulated cables placed inside special stainless-steel jackets.

Another technical problem constitutes the construction of a large cryostat for all superconducting coils, which should have about $29 \mathrm{~m}$ in diameter and

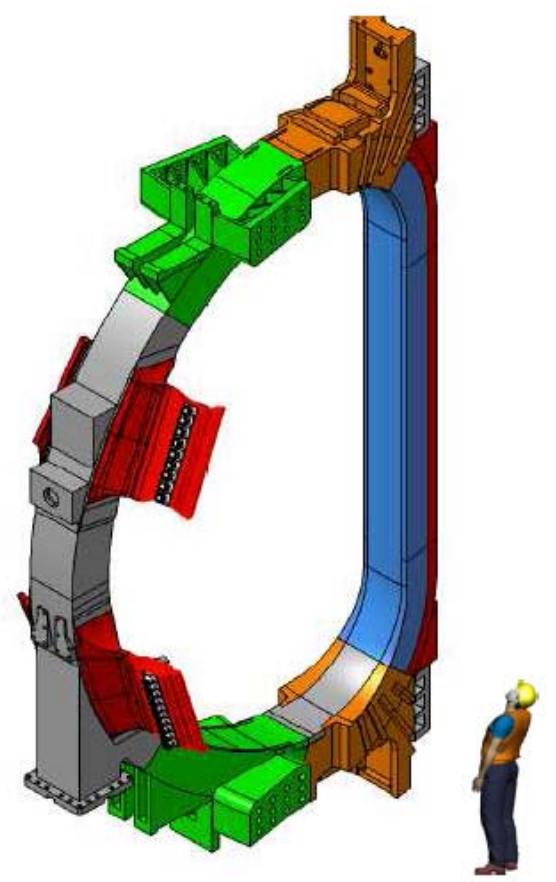

Fig. 7. Construction of the toroidal field coil of about $16 \mathrm{~m}$ in height and $9 \mathrm{~m}$ in width (total mass $360 \mathrm{t}$ ) [12].
$29 \mathrm{~m}$ in height. It must also be equipped with many ports needed for plasma heating and diagnostics. Different technical problems are also connected with the design and construction of plasma heating systems, and, in particular, with powerful microwave sources for the ion cyclotron resonance heating (ICRH, 40-55 MHz, $20 \mathrm{MW}$ ) and electron cyclotron resonance heating (ECRH, gyrotrons $170 \mathrm{GHz}, 20 \mathrm{MW})$. In the near future it will be necessary to solve also technical problems connected with the construction of 1-MeV neutral-beam injection (NBI, $33 \mathrm{MW}$ ) units, lower-hybrid heating ( $\mathrm{LH}, 5 \mathrm{GHz}, 40 \mathrm{MW})$ sources, and appropriate power supplies.

Difficult technical problems are connected with the design and construction of 40 various plasma diagnostic systems, and particularly those needed for the measurements of plasma density and temperature profiles as well as emission characteristics of fusion-produced neutrons. One should also mention technical problems connected with the construction of remote handling systems needed for in-vessel operation, as shown in Fig. 8.

The construction of an anti-seismic basement, designed for a 360 000-tonn ITER complex, is a very difficult task, but it has already been undertaken, as shown in Fig. 9.

Other technical problems are connected with the design and construction of an external Tritium Reprocessing Plant (7 floors building, $\mathrm{L}=80 \mathrm{~m}$, $\mathrm{W}=25 \mathrm{~m}, \mathrm{H}=35 \mathrm{~m}$ ), which might use existing technologies, but on a much larger scale (factor about 10). Some problems connected with large water-cooling and cryogenic plants, as well as large power-supply stations, must also be solved.

In spite of many technical problems described above, as well as necessary political and financial decisions, the ITER International Fusion Energy Organisation (IIFEO) agreement was reached in December 2005. Since the inception of the FP7 (Frame Programme) and the start of the building of ITER, the EU fusion budget has risen to $1947 \mathrm{M€}$ of which about $900 \mathrm{M} €$ have been consumed by the Euratom Associations and JET. In 2014, a new Fusion Programme has been initiated, which constitutes a

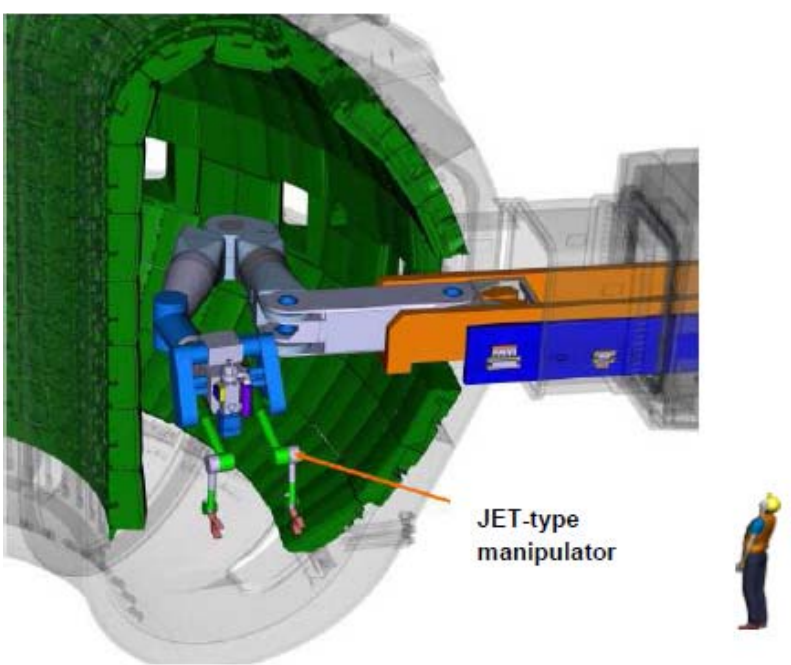

Fig. 8. Construction of a multi-purpose manipulator (deployer) for the remote handling in ITER [10]. 


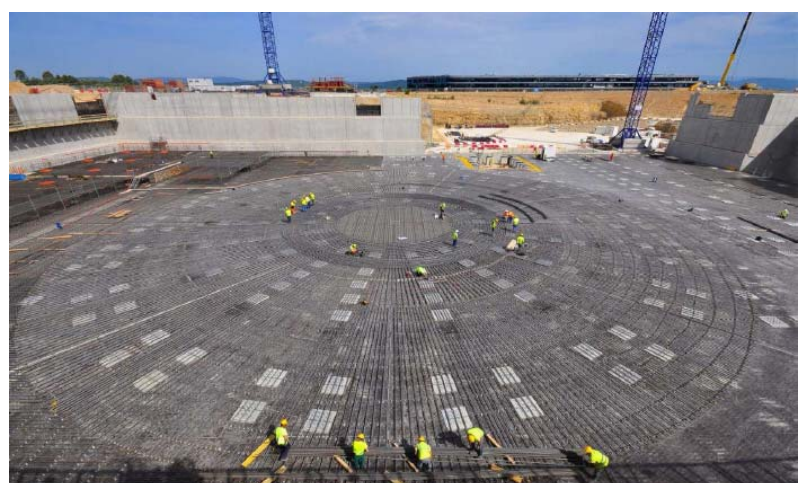

Fig. 9. Construction of the large basement (containing $15000 \mathrm{~m}^{3}$ of concrete) for ITER [12].

co-fund action for the implementation of the Roadmap on Fusion Energy Research under Horizon 2020. According to present estimates, the construction of ITER during next 30 years will consume above $15000 \mathrm{M€}$.

\section{Fusion fuel supplies}

In order to operate a thermonuclear reactor one must deliver appropriate amounts of deuterium and tritium, e.g., a large fusion power station generating $1500 \mathrm{MW}$ of electricity will consume about $400 \mathrm{~g}$ of deuterium and about $600 \mathrm{~g}$ of tritium. Power deposited by fast fusion-produced neutrons in the neutron blanket can be extracted by means of an appropriate heat exchange circuit and delivered to conventional electrical generators. Hence, one can easily image a scheme of a future thermonuclear power station, as shown in Fig. 10.

It should be noted that no serious problems connected with fusion fuel supplies are expected. Pure deuterium can be obtained from electrolysis of heavy water $\left(\mathrm{D}_{2} \mathrm{O}\right)$, which can relatively easily be separated from ordinary water, or from isotopic exchange in a hydrogen-sulphate gas. The separation of hydrogen isotopes can also be done by means of gas chroma-

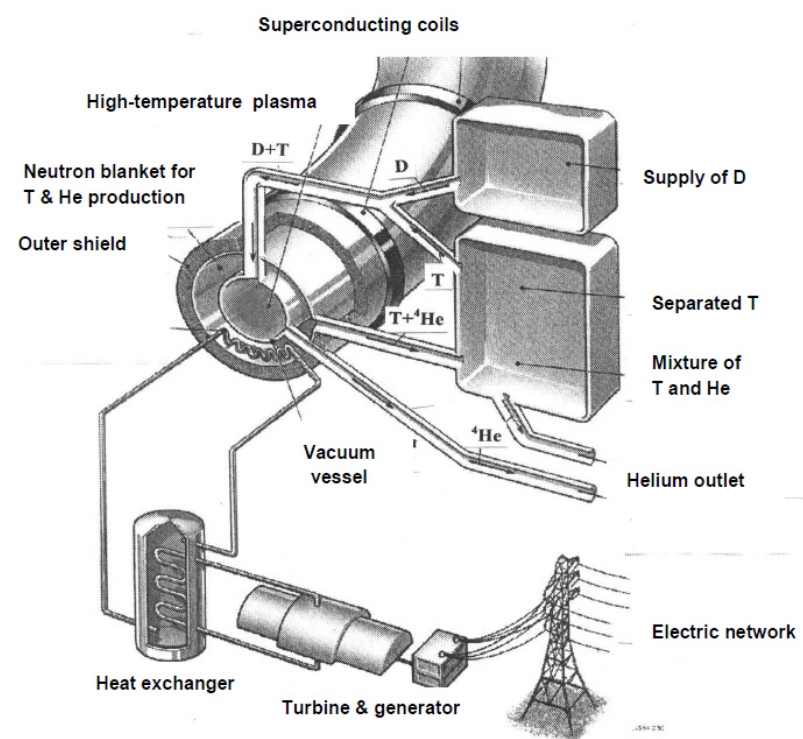

Fig. 10. Scheme of a future electric power plant based on the toroidal magnetic trap of the tokamak type [4].

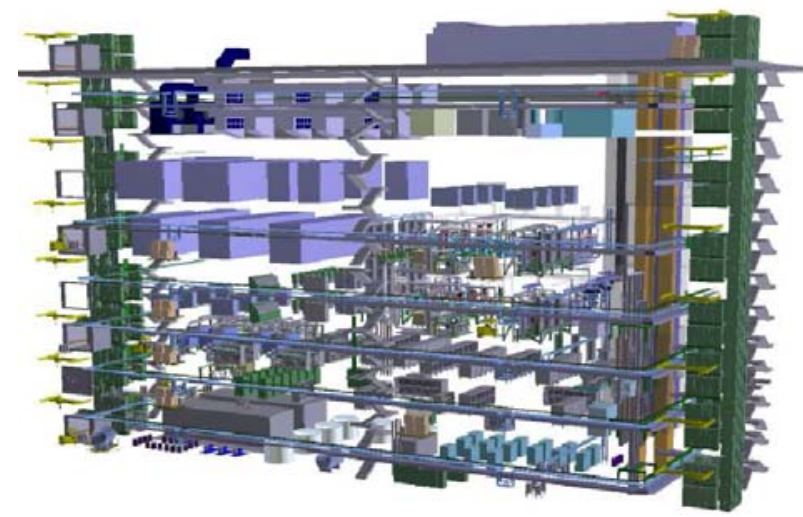

Fig. 11. Scheme of the large $(80 \mathrm{~m}$ in length, $35 \mathrm{~m}$ in height) tritium reprocessing plant (TRP) for ITER [10].

tography or cryogenic distillation. Since deuterium constitutes approximately $0.015 \%$ of hydrogen content in water, there is enough deuterium to produce energy for consumption for billion of years.

In contrary, tritium (due to its radioactive $\beta^{-}$decay, with a half lifetime equal to 12.3 years) cannot be stored in big amounts and for a long time, but it can be obtained from tritium breeding modules described above. It is estimated that for $400 \mathrm{~s}$ operation of ITER one will need an input of $54 \mathrm{~g}$ of tritium, and if $1 \mathrm{~g}$ of that is burnt the rest should be extracted through tritium breeding modules (TBM) and the external tritium reprocessing plant (TRP) described above. It should here be noted that a safety limit for in-vessel retention of tritium in ITER will amount to about 700 g only. Therefore, special techniques for deuterium and tritium removal from ITER internal components are now under development, e.g., laser cleaning of plasma-facing materials. It should here be noted that taking into account the present costs, it is estimated that the fusion fuel will contribute much less than $1 \%$ of the cost of electricity.

Other elements, which are needed for the fusion fuel cycle, can be found in various minerals. In particular, lithium necessary for the tritium breeding can be extracted from several minerals and from clays. Its natural deposits are particularly found in South America. The Earth's crust contains enough lithium for thousands of years, and the world seas also contain a huge supply of lithium.

The main problem is only the construction of efficient TBM and a safe TRP, but they might be built on the basis of the existing technology, although on a much larger scale, as shown in Fig. 11.

\section{Next generation of thermonuclear reactors}

The main aim of ITER, now under construction in Cadarache, France, is to produce a significant fusion power (about $500 \mathrm{MW}$ ), at the amplification factor $\mathrm{Q}=10$, during long (15-30 min) pulse operation. The second aim will be obtaining a steady state operation with $\mathrm{Q}=5$, and to test the possibility to achieve controlled fusion with higher $Q$ values (e.g. >30). The whole ITER complex will be not a thermonuclear power station, but a large experiment aiming to test technical components needed for a future 
fusion power plant (e.g. different tritium breeding modules) and to demonstrate the integrated operation of technologies for an industrial thermonuclear reactor. According to the present plans and funding, the ITER construction should be completed within a few years and after different operational tests (e.g. low-duty D-T operation, high-duty D-T operation etc.) the main operation phase should be initiated about 2025 .

A very important issue is the behaviour of first-wall materials, which should have a high thermal conductivity, high resistance to thermal shocks, high stability under neutron irradiation, low chemical erosion, oxygen remnants gettering (if possible), low affinity to deuterium and tritium towards formation of volatile products, and a low sorption of hydrogen isotopes. Therefore, particular attention must be paid to the investigation of different constructional materials. For this purpose, simultaneously with the ITER construction there are planned special facilities for material engineering studies, e.g. the International Fusion Material Irradiation Facility (IFMIF), which (using powerful deuteron accelerators and stripping reactions in a thick lithium target) might produce a very intense neutron flux (of the order of $10^{14} \mathrm{n} / \mathrm{s} \cdot \mathrm{m}^{2}$ ) [13]. The construction of IFMIF should be started simultaneously with the ITER construction, but because of a lack of funds this programme is delayed. Nevertheless, extensive material studies are carried out within different fusion laboratories.

In order to demonstrate the first commercial thermonuclear fusion reactor, extensive conceptual studies have already been undertaken. The main aim is to design and construct the so-called DEMO reactor with an output of electrical power of $1 \mathrm{GW}$ [14]. Since the engineering design of DEMO has already been started, if the $R \& D$ research is finished until 2030 and appropriate political and financial decisions are undertaken in proper time, then the DEMO might be constructed before 2050. The next step (in about 40 years) might be the design and construction of a commercial fusion reactor of the 2 nd generation (Fusion Reactor - type 2) [14]. Hence, the development of thermonuclear reactors can be presented in a diagram shown in Fig. 12.

\section{Summary and conclusions}

This paper can be summarized as follows: $1^{\circ}$. The world population is growing, fossil fuels are running out and the rise of $\mathrm{CO}_{2}$ concentration in the atmosphere threatens our climate. Hence, alternative $\mathrm{CO}_{2}$-free energy sources must be exploited, but taking into account limitations of 'green' energy sources (hydro-energy, wind and solar installations, etc.) as well as disadvantages of conventional nuclear reactors based on fission reactions, the only way is to develop thermonuclear reactors based nuclear fusion reactions of hydrogen isotopes; $2^{\circ}$. The most prospective seems now to be the construction of a thermonuclear reactor on the basis of a tokamak-type magnetic trap; $3^{\circ}$. The construction of the large ITER complex has already been started and this large physical and technological experiment is expected to produce 10 times more energy than needed for

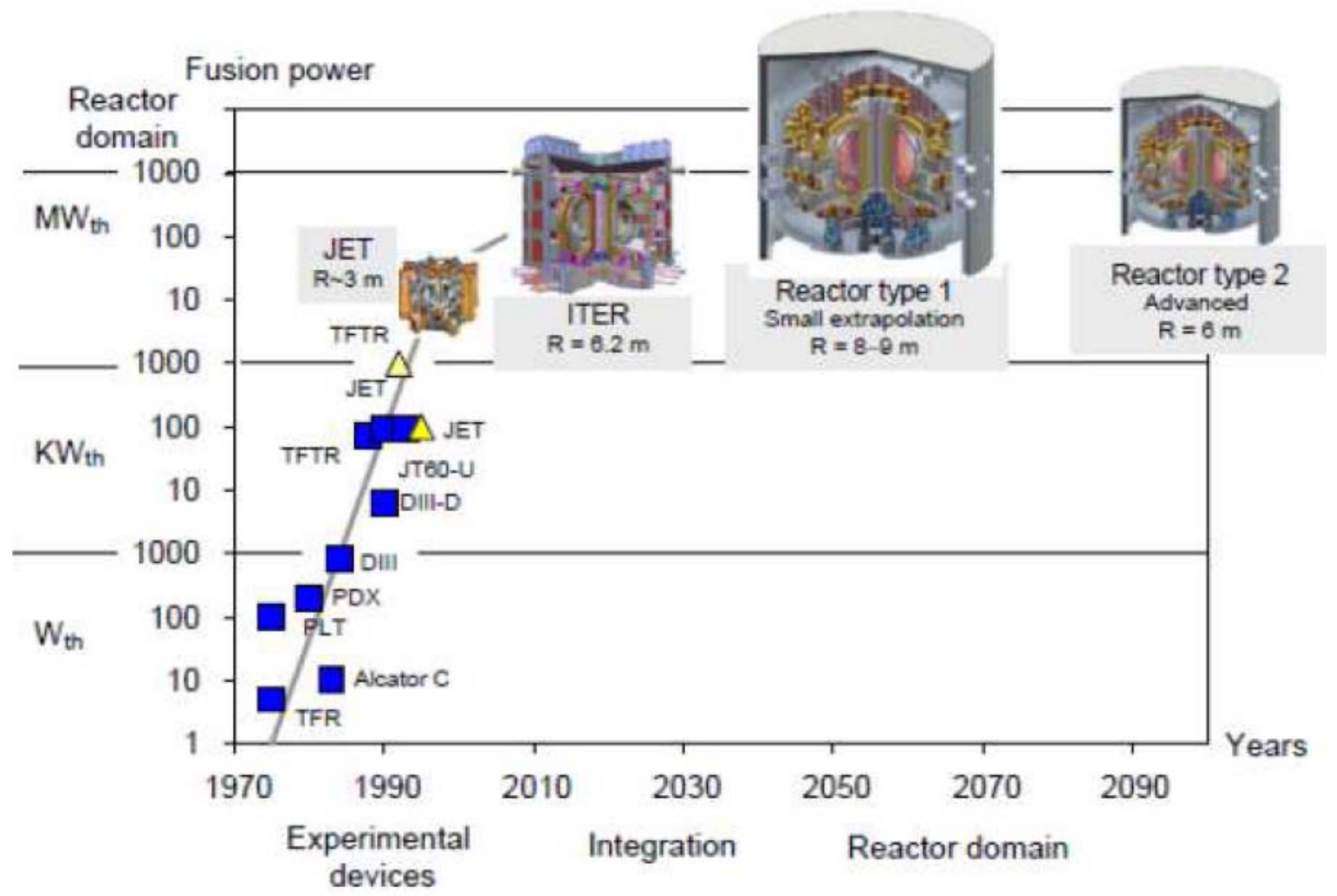

Fig. 12. History and plans for thermonuclear reactors in the coming years [2]. 
plasma heating during operation pulses lasting 15-30 minutes; $4^{\circ}$. After exploitation of ITER, the next steps should be the construction of the first commercial thermonuclear reactor DEMO, and subsequently the building of fusion-based reactors of the second generation (in the next $40-50$ years).

Acknowledgments. The elaboration of this paper was partly supported by the National Centre for Research and Development (NCBR) under contract no. SP/J/2/1443234. The views and opinions expressed herein do not necessarily reflect those of the ITER Organization.

\section{References}

1. Ongena, J. (2014). How to shape our future energy supply. In Proceedings of 12th Kudowa Summer School "Towards Fusion Energy", 9-13 June 2014, Kudowa Zdroj, Poland (p. IL-1). Warsaw: IPPLM. CD Issue.

2. Culham Centre for Fusion Energy, http://www.ccfe. ac.uk.

3. Conn, R. W., Chuyanov, V. A., Inoue, N., \& Sweetman, D. R. (1992). The International Thermonuclear Experimental Reactor. Sci. Am., 266(4), 103-110. DOI: 10.1038/scientificamerican0492-102.

4. Sadowski, M. J. (2005). Nuclear fusion - energy for future. Nukleonika, 50(Suppl. 3), S41-S52.

5. Vandenplas, P. E. (1980). Reflections on the past and future of fusion and plasma physics research. Plasma Phys. Contr. Fusion, 40, 77-85.
6. Rhodes, R. (1995). Dark Sun; The making of the hydrogen bomb. New York: Simon \& Schuster.

7. Sadowski, M. J., \& Scholz, M. (2012). Important issues of high-current plasma experiments of the Z-pinch type. Nukleonika, 57(1), 11-24.

8. Hurricane, O. A., Callahan, D. A., Casey, D. T., Celliers, P. M., Cerjan, C., Dewald, E. L., Dittrich, T. R., Döppner, T., Hinkel, D. E., Berzak Hopkins, L. F., Kline, J. L., Le Pape, S., Ma, T., MacPhee, A. G., Milovich, J. L., Pak, A., Park, H. -S., Patel, P. K., Remington, B. A., Salmonson, J. D., Springer, P. T., \& Tomassini, R. (2014). Fuel gain exceeding unity in an inertially confined fusion implosion. Nature, 506, 343-348. DOI: 10.1038/nature13008.

9. http://www.efda.org/2013/05/jet-the-joint-europeantorus/.

10. http://www.iter.org/proj\#milestones.

11. Todd, T. N. (2012). The engineering design of ITER. In Proceedings of 11th Kudowa Summer School "Towards Fusion Energy", 11-15 June 2012, Kudowa Zdroj, Poland. (p. IL-6), Warsaw: IPPLM. CD Issue.

12. Pinches, S. D. (2014). Physics challenges and status of ITER. In Proceedings of 12th Kudowa Summer School "Towards Fusion Energy", 9-13 June 2014, Kudowa Zdroj, Poland. (p. IL-6). Warsaw: IPPLM. CD Issue.

13. Garin, P., \& Sugimoto, M. (2011). IFMIF's new design; Status after 2 years of the EVEDA project. $J$. Nucl. Mater. 417(1/3), 1262-1266. DOI: 10.1016/j. jnucmat.2010.12.272.

14. Todd, T. N. (2014). The technical challenges of DEMO. In Proceedings of 12th Kudowa Summer School "Towards Fusion Energy", 9-13 June 2014, Kudowa Zdroj, Poland. (p. IL-15). Warsaw: IPPLM. CD Issue. 